\title{
Clinical Pharmacokinetics and Pharmacodynamics of Desmoteplase
}

\author{
Bartlomiej Piechowski-Jozwiak $^{1,2,3} \cdot$ Emna Abidi $^{4}{ }^{(} \cdot$ Wasim S. El Nekidy $^{2,4} \cdot$ Julien Bogousslavsky $^{5}$
}

Accepted: 21 November 2021 / Published online: 11 December 2021

(c) The Author(s), under exclusive licence to Springer Nature Switzerland AG 2021

\begin{abstract}
Desmoteplase is a bat (Desmodus rotundus) saliva-derived fibrinolytic enzyme resembling a urokinase and tissue plasminogen activator. It is highly dependent on fibrin and has some neuroprotective attributes. Intravenous administration of desmoteplase is safe and well tolerated in healthy subjects. Plasma fibrinolytic activity is linearly related to its blood concentration, its terminal elimination half-life ranges from 3.8 to $4.92 \mathrm{~h}(50 \mathrm{vs} .90 \mu \mathrm{g} / \mathrm{kg}$ dose). Administration of desmoteplase leads to transitory derangement of fibrinogen, D-dimer, alpha2-antiplasmin, and plasmin and antiplasmin complex which normalize within 4-12 h. It does not alter a prothrombin test, international normalized ratio, activated partial thromboplastin time, and prothrombin fragment 1.2. Desmoteplase was tested in myocardial infarction and pulmonary embolism and showed promising results versus alteplase. In ischemic stroke trials, desmoteplase was linked to increased rates of symptomatic intracranial hemorrhages and case fatality. However, data from "The desmoteplase in Acute Ischemic Stroke" Trials, DIAS-3 and DIAS-J, suggest that the drug is well tolerated and its safety profile is comparable to placebo. Desmoteplase is theoretically a superior thrombolytic because of high fibrin specificity, no activation of beta-amyloid, and lack of neurotoxicity. It was associated with better outcomes in patients with significant stenosis or occlusion of a proximal precerebral vessels. However, DIAS-4 was stopped as it might have not reached its primary endpoint. Due to its promising properties, desmoteplase may be added into treatment of ischemic stroke with extension of the time window and special emphasis on patients presenting outside the 4.5-h thrombolysis window, with wake-up strokes and strokes of unknown onset.
\end{abstract}

\section{Key Points}

Desmoteplase is a highly fibrin-dependent plasminogen activating agent.

Clinical research data support the safety of desmoteplase in thrombolysis between 3 and $9 \mathrm{~h}$ post-ischemic stroke onset.

There is positive evidence toward the effectiveness of desmoteplase in ischemic stroke patients with an MRI mismatch and proximal stenosis or occlusion.

Emna Abidi

AbidiEE@ClevelandClinicAbuDhabi.ae

1 Neurological Institute, Cleveland Clinic Abu Dhabi, Abu Dhabi, UAE

2 Cleveland Clinic Lerner College of Medicine of Case Western University, Cleveland, OH, USA

3 Department of Neurology, King's College Hospital, Denmark Hill, London SE5 9RS, UK

\section{Introduction}

\subsection{Acute Ischemic Stroke and Therapeutic Window}

Stroke is the second leading cause of mortality and morbidity, with one in six deaths from cardiovascular disease being due to all types of strokes in 2018 [1]. Moreover, every 40 $\mathrm{sec}$, a stroke is declared in the United States (US) and, every 4 min, a stroke-related death is documented in the US with a yearly count of more than 795,000 stroke cases. Approximately 610,000 cases of these are new-onset stroke cases, and an average of 185,000 ( 1 in 4) cases occur in people with a previous history of stroke [2]. Strokes affect $50 \%$ of survivors with a high rate of serious long-term disabilities worldwide [3] and represent a daily serious socio-economic

4 Department of Pharmacy, Cleveland Clinic Abu Dhabi, Abu Dhabi, UAE

5 Center for Brain and Nervous System Diseases (Neurocenter), Genolier Swiss Medical Network (Geneva, Lausanne, Glion, Genolier, Fribourg, Zurich), Clinique Valmont, 1823 Glion/Montreux, Switzerland 
burden in both developing and developed countries, with US $\$ 46$ billion stroke-attributed costs in the US between 2014 and 2015, including the cost of health care services, stroke treatment, and work absenteeism [2, 4]. Furthermore, ischemic strokes represent $87 \%$ of all stroke etiologies, leading to brain function loss and to a large extent of different pathophysiological manifestations secondary to cerebral ischemia [2]. Most stroke-related disabilities are largely due to late-stage diagnosis $[5,6]$, as well as to costly medication with limited availability, and the narrow therapeutic window. In fact, there is currently only one agent approved for the treatment of acute ischemic stroke within the first $4.5 \mathrm{~h}$ after onset: alteplase (recombinant tissue plasminogen activator; rtPA) [7, 8].

Intra-arterial (IA) or intravenous (IV) administration of different thrombolytic agents, such as streptokinase, urokinase, and recombinant urokinase have been studied without any satisfactory results [9]. Furthermore, neurologic and radiologic outcomes with IV tenecteplase were similar to those with alteplase when the drugs were administered within $4.5 \mathrm{~h}$ after symptom onset in patients with acute ischemic stroke [10].

Nonetheless, recent studies, such as the Prolyse in Acute Cerebral Thromboembolism (PROACT) study, reported an improved clinical outcome at 90 days of treatment with IA recombinant prourokinase administration, within $6 \mathrm{~h}$ of the onset of acute ischemic stroke [11]. Moreover, Alison et al. [12] reported a probability of tenecteplase to be superior to rtPA for large vessel reperfusion in patients with salvageable penumbra. Similar results were reported by Fana et al. [13], showing that tenecteplase may increase the rate of reperfusion in comparison with rtPA, prior to endovascular thrombectomy in patients with basilar artery occlusion. However, the reported findings still need to be translated into improved clinical outcomes. Furthermore, due to real-life difficulties in stroke patients reaching the hospital in time, including out-of-hospital and in-hospital delays, thrombolysis with alteplase may not be possible in all patients within the 4.5-h time window $[14,15]$. The impact of the extension of the thrombolysis time window from 3 to $4.5 \mathrm{~h}$, using data from the Safe Implementation of Treatments in Stroke-International Stroke Thrombolysis Registry and the third European Cooperative Acute Stroke Study, was very significant $[15,16]$.

Moreover, according to Maestroni et al., the average delay from stroke onset to hospital arrival is $5.4 \mathrm{~h}$ (interquartile range $2.7-11.6$ ); $28 \%$ of patients arrive within $3 \mathrm{~h}$ and 53\% within $6 \mathrm{~h}$ post-stroke onset [17]. Recently, a significant increase in the mean interval between the 'lastknown-well' timepoint (LKW) and the time of presentation of a stroke patient to the hospital was attributed to the current COVID19 pandemic. In fact, public measures to limit the spread of COVID-19, such as the worldwide imposed social distancing, telemedicine facilitation, or shelter-in-place orders, as well as stay-at-home policies, have had unwanted repercussions on proper on-time reactions to a stroke onset, and have increased delayed care and detrimental outcomes [18].

The same study has reported a significant 160 -min average increase $(P<0.03)$ in mean LKW-presentation interval between March 2020, a period of COVID-19 $(603 \pm 1035 \mathrm{~min})$, when compared to 2 months (February-March 2019) of no COVID-19 baseline period $(442 \pm 435 \mathrm{~min})$ [18].

Moreover, a future additional re-emergence of COVID19 or resurrection of other pandemic outbreaks could occur and affect the ability to seek medical help shortly after symptoms onset, and are reasons to point to the limitation related to the use of alteplase. However, currently available alternatives to alteplase are still limited to endovascular reperfusion therapy, such as mechanical embolectomy [19]. Nevertheless, this kind of stroke management entails high costs and requires developed facilities and highly skilled professionals [20,21]. Thus, pharmacological procedures with wider times windows (above $4.5 \mathrm{~h}$ ), replacing mechanical ones, require further investigation.

In this review, we highlight, discuss, and summarize the potential of desmoteplase as a promising pharmacological intervention which, in resource-limited contexts, as well as when other pharmacological thrombolysis is contraindicated, or might be ineffective, can commonly be used as an alternative therapy in acute ischemic stroke. In December 2014, Lundbeck discontinued the development of desmoteplase in acute ischemic stroke due to insufficient clarity regarding the enrolment of patients in future prospective trials [22]. However, the study of desmoteplase pharmacodynamics has recently regained much more interest, and clinical and translational studies are taking place in order to decipher the unknown about the dose versus effect of desmoteplase as a thrombolytic agent in stroke patients.

A literature review was conducted following simple search strategies to identify peer-reviewed literature (e.g., peer-reviewed articles, database-specific filters) by relative search terms as well as Boolean logic used to combine search terms. Three databases $\left(\right.$ PubMed $^{\circledR}$, CINAHL, and Cochrane) were used for the search.

These databases were identified because they represented comprehensive repositories of citations, abstracts, and relevant full articles.

Moreover, hospital databases have also been explored to access some useful tools, such as Lexicomp, Micromedex, and other drug information portals, providing evidencebased referential drug information. The latest literature search was performed in August 2021. 


\subsection{Development of Desmoteplase}

\subsubsection{Discovery and Structure}

With the silver jubilee of alteplase as the unique thrombolytic agent, Reed et al. [23] outlined the indications, contraindications, activity, adverse events, and toxicity associated with rtPA therapy. In fact, the adverse event profile and potential for toxicity, such as neurotoxicity and increased bleeding risks, as well as its only 5-min half-life [23-25], have encouraged efforts over the past 25 years to discover new pharmacological therapies, such as new modified tissue plasminogen activators. An exhaustive list of those contains reteplase, tenecteplase, desmoteplase, monteplase, pamiteplase, lanoteplase, and alfimeprase [26, 27]. Of this list, tenecteplase and desmoteplase have proved promising treatment potentials with increased safety and efficacy at $24 \mathrm{~h}$ and 90 days.

In fact, both agents have shown increased plasma halflives and fibrin specificity, improved resistance to plasminogen activator inhibitors, and almost no neurotoxicity [28]. Tenecteplase allows better reperfusion and recanalization [29], as well as an expansion of the treatment window to $6 \mathrm{~h}$. Phase 2 and phase 3 trial confirmations have been obtained for tenecteplase [30, 31]. Desmoteplase is another thrombolytic agent which underwent active phase III research to meet the requirements of an extended time window up to $9 \mathrm{~h}$ from stroke onset. The discovery of desmoteplase came from the observation of vampire bats (Desmodus rotundus) needing uninhibited blood flow to satisfy their hunger, which is achieved by hemostatic modulators in their saliva.

This was investigated in the late 1990s by Gardell, who found that bat-derived salivary plasminogen activator was homologous to human tissue plasminogen activator (rtPA) $[32,33]$. A complete DNA coding of four plasminogen activators present in the saliva of the vampire bat was achieved by 1991 . Three desmoteplase species have been isolated, and these molecules were found to be as effective as rtPA in activating plasminogen in the presence of fibrin [34]. The desmoteplase family $(\alpha 1, \alpha 2, \beta, \gamma)$, relatively smaller fibrinolytic agents, are structurally similar to urokinase plasminogen activator (uPA) and rtPA. The common modules of the desmoteplase family include epidermal growth factor $(\mathrm{E})$, finger $(\mathrm{F})$, kringle $(\mathrm{K})$, and protease $(\mathrm{P})$. These modules yield four distinct isoenzymes with the following distinctive phenotypes: FEKP for desmoteplase $\alpha 1$ and $\alpha 2$, EKP for desmoteplase $\beta$, and KP for desmoteplase $\gamma$ [35]. The amino acid sequence among these four isoenzymes is very similar, with $88.7-99.5 \%$ identity despite phenotypic differences [36].

Interestingly, the amino acid sequence of rtPA is closely related to desmoteplase $\alpha 1$ (72.3\%) and desmoteplase $\alpha 2$ (74.2\%). Unlike rtPA, all four DSPA isoenzymes contain just one lysine-binding kringle $2 \mathrm{~K}$ domain (two domains in rtPA) [35]. Desmoteplase $\alpha 1$ and $\alpha 2$ isoforms differ in amino acid substitutions by $11 \%$, mainly in the $\mathrm{F}, \mathrm{E}$, and $\mathrm{K}$ domains. Desmoteplase $\beta$ and $\gamma$ are similar to desmoteplase $\alpha 2$ but have 2 and 13 amino acid exchanges ( $\beta$ and $\gamma$, respectively) [37, 38]. The chemical and configurational aspects of rtPA and desmoteplase are shown in Figs. 1 and 2.

\subsubsection{Desmoteplase versus rtPA}

Of the four desmoteplase isoenzymes, only $\alpha 1$ and $\alpha 2$ bind to fibrin. In contrast to rtPA, the $\mathrm{N}$-terminal region plasmin-sensitive activation site is absent on all desmoteplase isoenzymes, which is why they activate plasminogen as single chain molecules. This latter property renders desmoteplase administration safe from any negative effect on the blood-brain barrier. Moreover, the desmoteplase halflife is of about $4 \mathrm{~h}$ compared to $5 \mathrm{~min}$ for rtPA [40]. The unique feature of desmoteplase isoenzymes when compared to rtPA is their requirement for a fibrin cofactor. Two desmoteplase isoforms, namely $\alpha 1$ and $\alpha 2$, have demonstrated at least comparable, if not superior, thrombolytic activity, lower fibrinogen degradation, and $\alpha 2$-antiplasmin use when compared to rtPA. In a study by Bringmann et al. [36], the addition of fibrin increased the catalytic efficiency of desmoteplase $\alpha 1$ 100,000-fold, which was almost 2000 times more when compared with rtPA.

The ratio of catalytic efficiencies in the presence of fibrin compared to those in the presence of fibrinogen was 12,900 for desmoteplase $\alpha 1,6550$ for $\alpha 2,235$ for $\beta$, and 90 for $\gamma$; this ratio was of 72 for rtPA. This finding has already pointed toward very high fibrin specificity of desmoteplase isoenzymes [35]. A peer-reviewed literature search led by Piechowski-Jozwiak and Bogousslavsky [37] about the use of desmoteplase in the treatment of ischemia reported a 50,000 -fold increase in vitro desmoteplase $\alpha 1$ activity in the presence of fibrin in comparison to a 100-fold enhancement for rtPA. Similar results were previously reported by Schleuning et al. [38].

Recently, Elmira et al. [42] reported new thrombolytic drugs with engineered properties aiming, specially, to enhance fibrin affinity and specificity and to increase halflife. In this study, protein engineering and cutting-edge theoretical methods allowed the design of three-dimensional structures of wild-type reteplase based on homology modeling. The newly developed structures contained the finger domain of desmoteplase as a high fibrin-specific domain. This design aimed to achieve enhanced fibrin affinity and other potential properties, such as decreased neurotoxicity and increased resistance to plasminogen activator inhibitor-1. Experimental assessment showed a 1.9-fold increase in fibrin binding ability, as well as appropriate enzymatic activities in both chemeric reteplase 

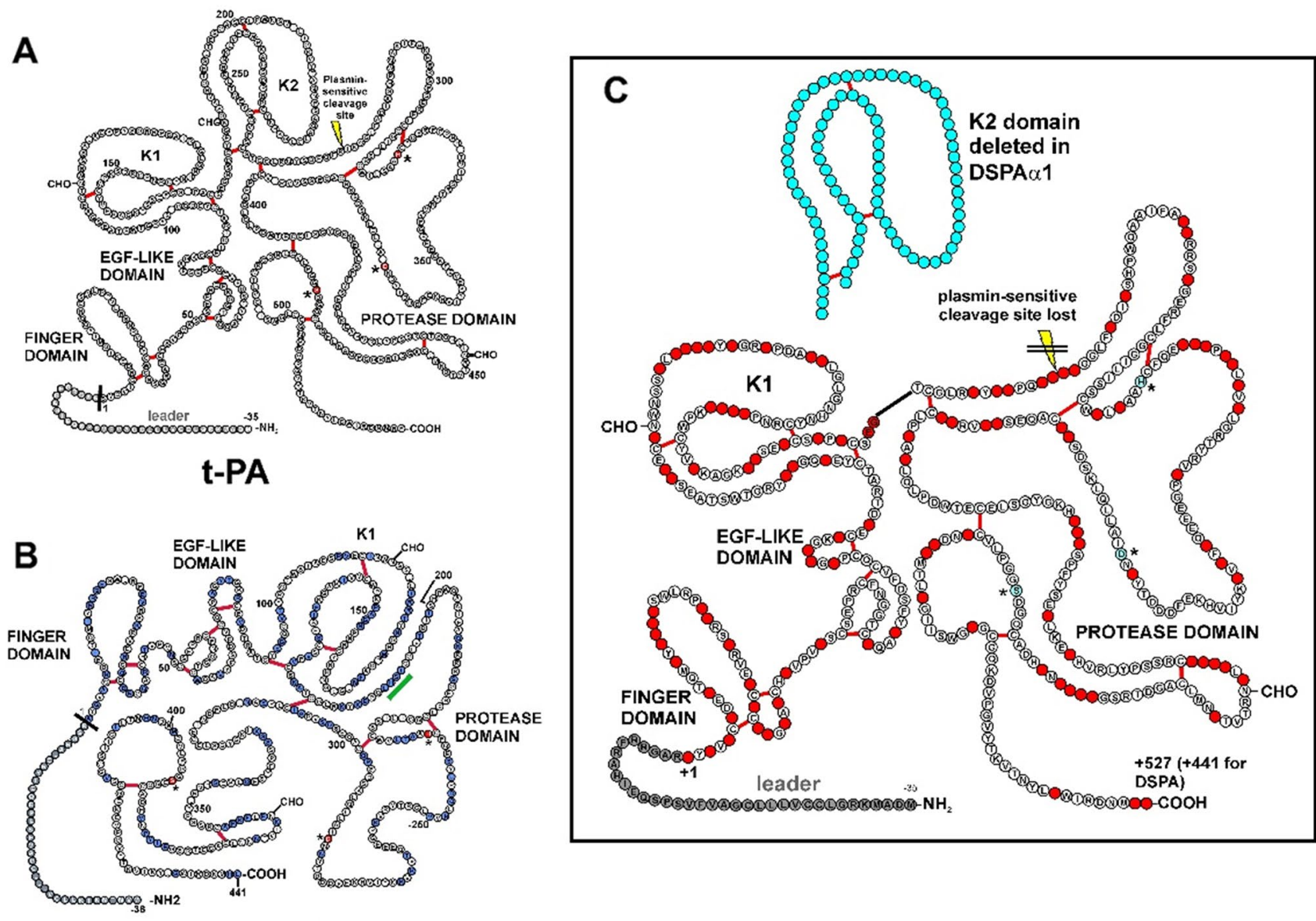

DSPA $\alpha 1$

Fig. 1 Schematic of recombinant tissue plasminogen activator (rtPA) (A) and desmoteplase [DSPA] $(\alpha 1)(\mathbf{B})$ showing the finger, epidermal growth factor (EGF), kringle (K), and protease domains. Residues colored red and noted with an asterisk in rtPA indicate the catalytic triad (His, Asp, Ser). The corresponding residues on desmoteplase $\alpha 1$ are also indicated with an asterisk and colored red. Amino acid substitutions in desmoteplase $\alpha 1$ that differ from t-PA are colored blue in

compared to wild-type [41]. Here again, desmoteplase showed a promising alternative for future production of effective thrombolytics with very low neurotoxic activity. Moreover, in an animal model of NMDA-induced injury of basal ganglia, administration of desmoteplase $\alpha 1$ did not induce an excitotoxic effect and neuronal death, which was the case after the administration of alteplase [37, 40, 42, 43].

In addition, the desmoteplase $\alpha 1$ isoenzyme has some more favorable properties over rtPA. The latter crosses the blood-brain barrier via a receptor-mediated process through low-density lipoprotein receptor-related protein (LRP)-dependent transcytosis.

Tissue plasminogen activator can cause blood-brain barrier leakage and led to the passage of rtPA into brain parenchyma under metabolic deprivation in an animal
B. The green line adjacent to residues 188-191 (LHST) in B indicates the lost plasmin cleavage site. Disulphide bonds are shown as red lines. Inset in $\mathbf{C}$ differences between rtPA and desmoteplase $\alpha 1$ are shown based on the t-PA structure. Substituted residues are shown in red. The catalytic triad (His, Asp, Ser) is again noted with asterisks. $\mathrm{CHO}$ glycosylation site. (Reprinted with permission) [39]

stroke model. The blood-brain barrier passage of desmoteplase $\alpha 1$ is also based on a LPR-mediated route. Thus, desmoteplase $\alpha 1$ antagonizes the neurotoxicity induced by vascular rtPA by competing at the LPR binding site [43].

\section{Pharmacokinetics of Desmoteplase}

In a phase I trial, Larsen et al. studied the pharmacokinetics of IV desmoteplase in healthy Caucasian and Japanese men [44].

At screening, all the patients had brain MRI, blood pressure assessment, and ECG. The single ascending dose study design included two different cohorts of participants: a first cohort of Caucasian men, randomized to receive IV desmoteplase $50 \mu \mathrm{g} / \mathrm{kg}$ injection $(n=6)$ or placebo $(n=3)$, and 


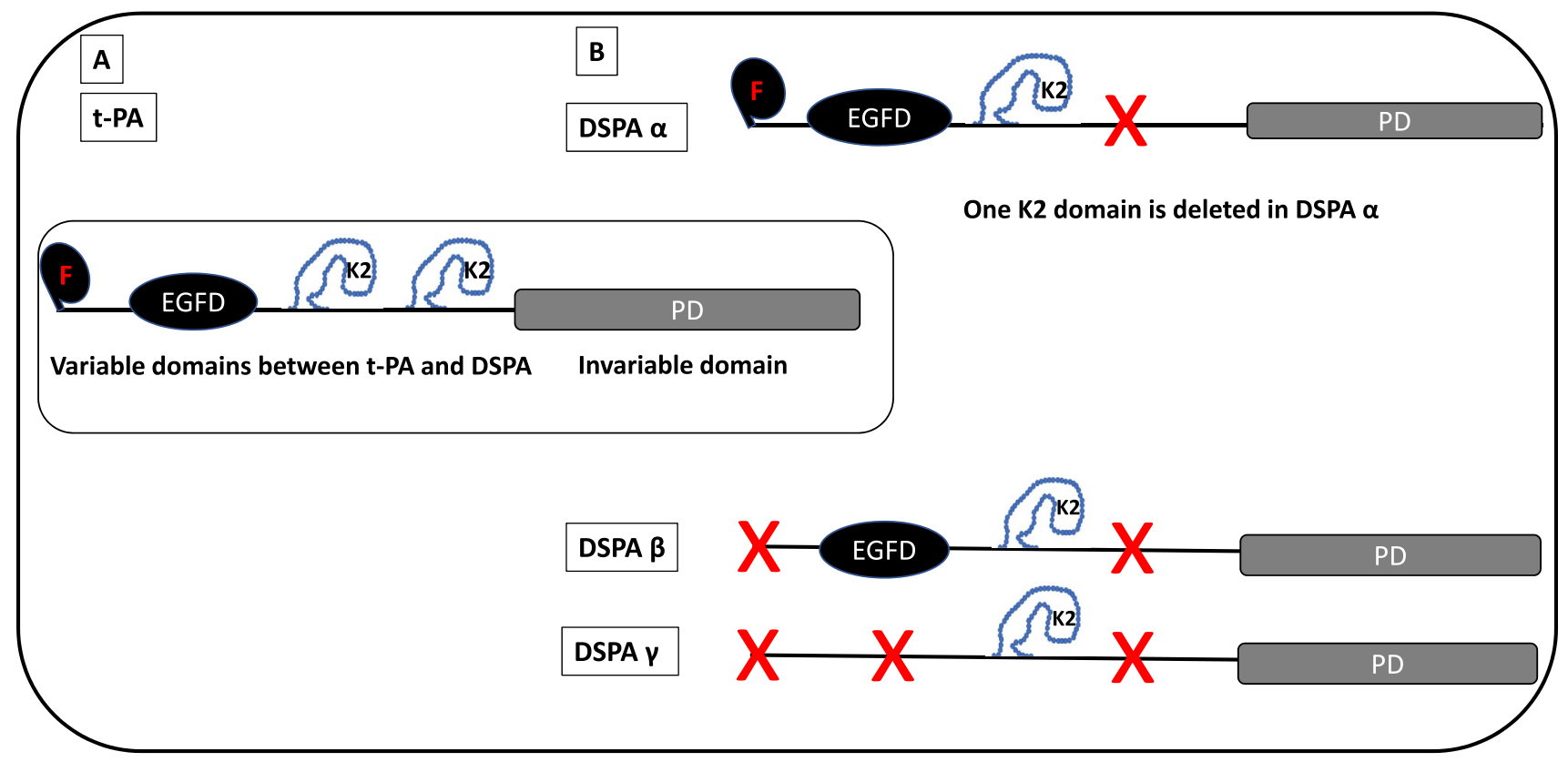

Fig. 2 Schematic of desmoteplase (DSPA) $\alpha, \beta$ and $\gamma$ compared with tissue plasminogen activator (t-PA). Structural domains: $F$ finger domain, $E G F D$ epidermal growth factor domain, $K$ kringle domain, $P D$ protease domain

a second one of Japanese men randomized per dosage group of IV desmoteplase $50 \mu \mathrm{g} / \mathrm{kg}(n=6), 70 \mu \mathrm{g} / \mathrm{kg}(n=6)$, and $90 \mu \mathrm{g} / \mathrm{kg}(n=6)$ or placebo $(n=3)$. For both cohorts, each desmoteplase dose was increased after assessing the safety and tolerability of the previous dose. Pharmacokinetic parameters were found to be similar in both Japanese and Caucasian men after a single IV dose of $50 \mu \mathrm{g} / \mathrm{kg}$ desmoteplase, although a 13\% difference of the AUC between the Caucasian versus Japanese subjects needs to be noticed. The pharmacokinetics data are detailed in Fig. 3.

Recently, a Russian review mentioned desmoteplase as one of the latest modified variants of a tissue plasminogen activator with a prolonged clearance time, high fibrinselectivity, and bolus delivery, to be used in acute ischemic stroke treatment [45]. Moreover, Deborah et al. [46] tested the corneal and scleral permeability of desmoteplase ex vivo both in different animal species and in humans. The rationale behind this study was mainly the documented failure of rtPA to reach fibrinolytic concentrations that are capable of resolving intraocular fibrin. The authors' choice of desmoteplase relied on its structural similarity to rtPA, but its smaller molecular weight as a fibrinolytic agent with a higher fibrin selectivity, longer half-life, and especially its higher biocompatibility. Results of this study have reported a higher ability of desmoteplase to permeate both cornea and sclera ex vivo in all the species tested, ranging, respectively, from 0.0 to $16.3 \mu \mathrm{g} / \mathrm{mL}$ and 0.0 to $11.4 \mu \mathrm{g} / \mathrm{mL}$ in rabbits, 0.3 to $5.6 \mu \mathrm{g} / \mathrm{mL}$ and 3.1 to $9.2 \mu \mathrm{g} / \mathrm{mL}$ dogs, 2.1 to $14.9 \mu \mathrm{g} / \mathrm{mL}$ and 4 to $8.7 \mu \mathrm{g} / \mathrm{ml}$ in horses, and 0.6 to $3 \mu \mathrm{g} /$
$\mathrm{mL}$ and 2.9 to $18.1 \mu \mathrm{g} / \mathrm{mL}$ in pigs. Preserved human corneas showed concentrations ranging from 0.07 to $12.9 \mu \mathrm{g} / \mathrm{mL}$ of desmoteplase after diffusion through tissue culture, suggesting that in vivo permeability may be possible [46].

\section{Clinical Pharmacodynamics of Desmoteplase}

The pharmacodynamics of desmoteplase were also studied by Larsen et al. [44], who found that coagulation markers demonstrated similar responses in Caucasian and Japanese subjects following an IV $50 \mu \mathrm{g} / \mathrm{kg}$ dose. In comparison with placebo, there were no apparent changes of prothrombin time, international normalized ratio, activated partial thromboplastin time, and prothrombin fragment 1.2 following injection of any dose of desmoteplase. There was a dip of plasma fibrinogen levels from $2.5 \mathrm{~g} / \mathrm{L}$ (range 1.96-3.53) to $1.6 \mathrm{~g} / \mathrm{L}(1.03-2.42)$ observed $5 \mathrm{~min}$ after administration. Normalization was seen between 2 and $4 \mathrm{~h}$, even with the highest dose of $90 \mu \mathrm{g} / \mathrm{kg}$.

The plasma level of alpha2-antiplasmin dropped from $101 \%(97-106 \%)$ to $73 \%(68-89 \%)$ at $5 \mathrm{~min}$ after dose administration and normalized after $1 \mathrm{~h}(90 \mu \mathrm{g} / \mathrm{kg}$ dose). Plasma plasminogen levels dropped from $97 \mathrm{~g} / \mathrm{L}$ $(87-111 \mathrm{~g} / \mathrm{L})$ to $78 \mathrm{~g} / \mathrm{L}(60-96 \mathrm{~g} / \mathrm{L}) 5 \mathrm{~min}$ post-administration and normalized at $2-4 \mathrm{~h}(90 \mu \mathrm{g} / \mathrm{kg}$ dose $)$. There was a dose-related increase of D-dimer from a variable baseline $(21-274 \mu \mathrm{g} / \mathrm{L})$ : the maximum mean increases up 


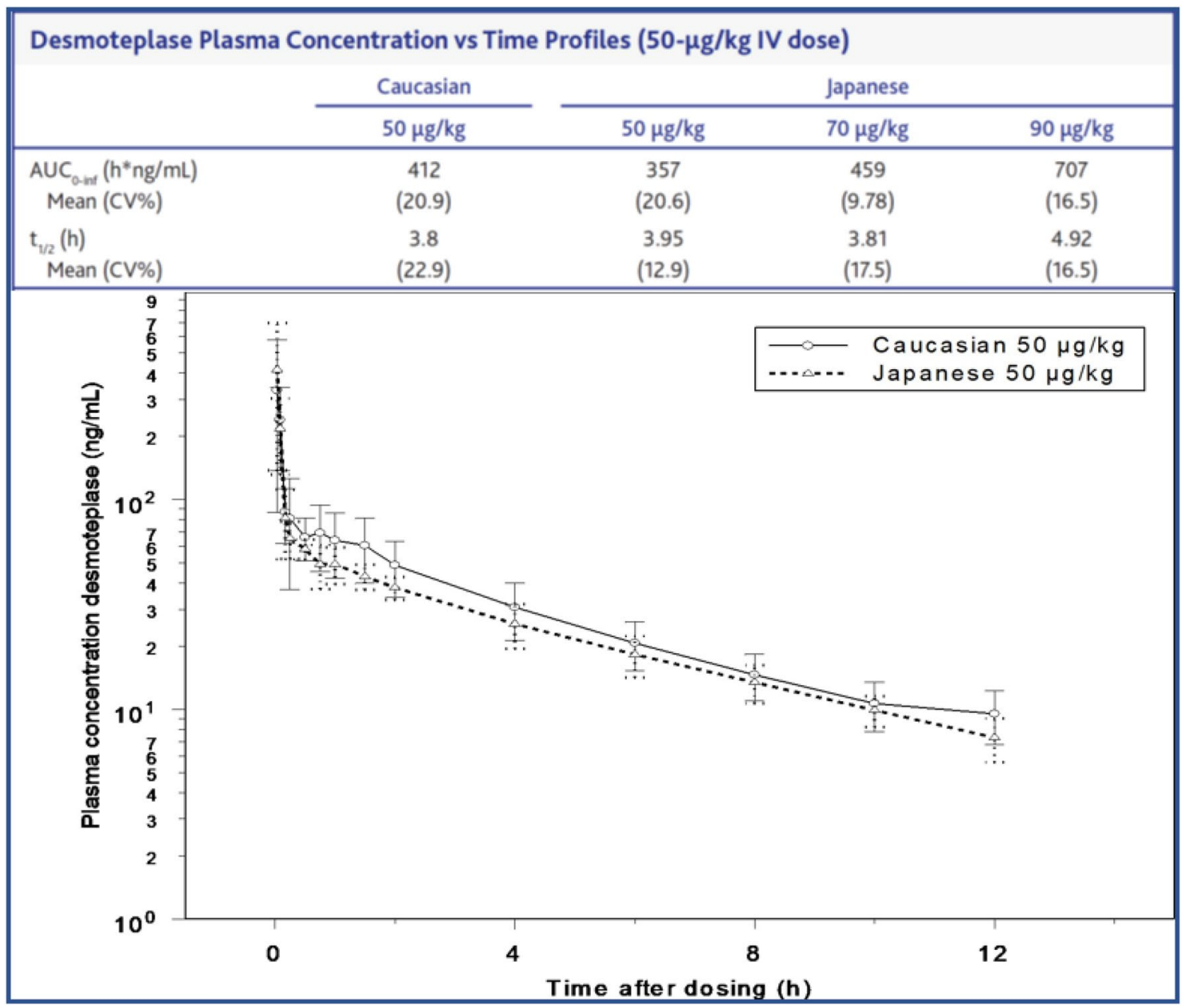

Fig. 3 Similar pharmacokinetic parameters between Japanese and Caucasian men after a single IV dose of $50 \mu \mathrm{g} / \mathrm{kg}$ desmoteplase. However, there is also a difference in AUC between the same groups

to $4 \mathrm{~h}$ post-dose were 14-fold (287-6423 $\mu \mathrm{g} / \mathrm{L})$ for $50 \mu \mathrm{g} /$ $\mathrm{kg}$, 26-fold (145-6426 $\mu \mathrm{g} / \mathrm{L})$ for $70 \mu \mathrm{g} / \mathrm{kg}$, and 47 -fold (147-11011 $\mu \mathrm{g} / \mathrm{L})$ for $90 \mu \mathrm{g} / \mathrm{kg}$ doses. The plasma plasmin-antiplasmin complex levels showed a dose-related increase from baseline $(234-298 \mu \mathrm{g} / \mathrm{L})$ of approximately six-fold (1198-1987 $\mu \mathrm{g} / \mathrm{L})$ for $50 \mu \mathrm{g} / \mathrm{kg}$, seven-fold (2012-3738 $\mu \mathrm{g} / \mathrm{L})$ for $70 \mu \mathrm{g} / \mathrm{kg}$, and eight-fold (2156-3994 $\mu \mathrm{g} / \mathrm{L})$ for $90 \mu \mathrm{g} / \mathrm{kg}$ IV doses at $5 \mathrm{~min}$ post-administration. All these values normalized at $12 \mathrm{~h}$. A strong correlation between plasma fibrinolytic activity and plasma concentration of desmoteplase was reported at all doses in both the ethnic groups studied (Pearson correlation range between 0.813 and 0.978 ). Overall, desmoteplase was safe and well tolerated; only two subjects had adverse events probably related to desmoteplase, consisting of a mild headache and hematoma [44].

Pharmacokinetics and pharmacodynamics of desmoteplase with other well-known thrombolytic agents are
(412 vs. $357 \mathrm{~h} \times \mathrm{ng} / \mathrm{mL}$ ): $A U C_{0 \text {-inf }}$ area under the plasma concentration-time curve extrapolated to infinity; $t_{1 / 2}$ half-life; $C V \%$ coefficient of variation expressed in \%. (Reprinted with permission) [44]

compared in Table 1, showing a longer half-life of desmoteplase and a slower clearance, both in line with bolus administration of this medication. Table 1 also shows differences in fibrin selectivity and plasminogen activator inhibitor effects between these agents.

\section{Clinical Efficacy and Safety}

Desmoteplase was studied in different clinical indications such as myocardial infarction, pulmonary embolism, and ischemic stroke [37].

\subsection{Results of Clinical Trials}

One open-label phase II clinical study in 26 patients assessed the efficacy, safety, and tolerability of IV (bolus of 0.5 or $0.75 \mathrm{mg} / \mathrm{kg}$ ) desmoteplase $\alpha 1$ for thrombolysis after acute 
Table 1 Comparison of pharmacokinetics and pharmacodynamics of selected thrombolytics [48, 49]

\begin{tabular}{lllllll}
\hline & Mol. weight $(\mathrm{kD})$ & $\begin{array}{l}\mathrm{t}_{1 / 2} \\
(\mathrm{~min})\end{array}$ & $\begin{array}{l}\text { Clearance } \\
\mathrm{ml} / \mathrm{min}\end{array}$ & Elimination & Fibrin selectivity & PAI-1 inhibition \\
\hline Urokinase & $32 / 54$ & 2 & $179 \pm 55$ & Liver & - & +++ \\
rtPA & 68 & 5 & $550-680$ & Liver & ++ & +++ \\
Tenecteplase & 65 & 25 & $119 \pm 49$ & Liver & +++ & - \\
Desmoteplase & 52 & 168 & 168.3 & Liver & ++++++ & $?$ \\
\hline
\end{tabular}

myocardial infarction. The rate of recanalization achieved was $65 \%$ [47].

Another phase II study compared the thrombolytic efficacy and safety of desmoteplase IV administration (125, 180 , and $250 \mu \mathrm{g} / \mathrm{kg}$ ) with alteplase (100 mg) in 34 patients with pulmonary embolism. This study showed that desmoteplase at doses of 180 and $250 \mu \mathrm{g} / \mathrm{kg}$ had similar or greater efficacy compared with alteplase $100 \mathrm{mg}$, with a faster onset of action and comparable safety [50]. Moreover, the current license of alteplase allows for a 4.5 -h time window. However, there is a significant unmet demand for effective thrombolytic treatment for both patients presenting out of the current alteplase time window, including wakeup patients with unknown time of onset, and patients with known time of onset but above 4.5-6 h (Fig. 4) [37, 51].

On the other hand, desmoteplase treatment allows a longer therapeutic window $(>4.5 \mathrm{H})$ for stroke patients with no safety concerns. Desmoteplase in the Acute Ischemic Stroke Trial (DIAS) was a phase II, dose-finding, placebocontrolled, MRI-based study with a 3- to 9-h time window. This study was originally designed to investigate three fixed IV doses of desmoteplase; $25 \mathrm{mg}, 37.5 \mathrm{mg}$, and $50 \mathrm{mg}$ versus placebo.

However, due to an excessive and unexplained bleeding rate $(26.7 \%)$ the study was stopped. The new protocol in Part-2 DIAS included a bodyweight-adjusted dose escalation design with the following IV doses: $62.5 \mu \mathrm{g} / \mathrm{kg}, 90 \mu \mathrm{g} /$ $\mathrm{kg}$, and $125 \mu \mathrm{g} / \mathrm{kg}$.

Reperfusion rates were up to $71.4 \%$ with $125 \mu \mathrm{g} / \mathrm{kg}$ desmoteplase versus $19.2 \%$ in the placebo arm. Favorable 90-day clinical outcome was seen in $22.2 \%$ of the placebo arm versus $13.3 \%$ in the $62.5 \mu \mathrm{g} / \mathrm{kg}$ and $60 \%$ in the $125 \mu \mathrm{g} /$ $\mathrm{kg}$ groups $(p=0.0028)$. Much less symptomatic intracranial hemorrhage (sICH) (2.2\%) was reported in this study. Moreover, better reperfusion outcome was achieved in $60 \%$ of patients treated with desmoteplase versus $22.2 \%$ in the placebo group [37-52]. In addition, the placebo-controlled Dose Escalation of Desmoteplase for Acute Ischemic Stroke study (DEDAS) evaluated the safety and efficacy of 90 and $125 \mu \mathrm{g} / \mathrm{kg}$ IV desmoteplase within 3- to 9-h post-stroke onset.

Eligibility criteria included a National Institutes of Health Stroke Scale score of 4-20 and MRI perfusion/diffusion mismatch, a total of 37 patients were enrolled. The primary endpoints were sICH, MRI reperfusion, and a good clinical outcome at 90 days. No sICH were reported in this study. Reperfusion was achieved in $37.5 \%$ of placebo patients versus $18.2 \%$ in $90 \mu \mathrm{g} / \mathrm{kg}$ and $53.3 \%$ in $125 \mu \mathrm{g} / \mathrm{kg}$ groups. Good clinical outcome was seen in $25 \%, 28.6 \%$, and $60 \%$ of patients, respectively. However, none of these results was statistically significant $[37,51,53]$.

DIAS-2 was a randomized, placebo-controlled, doubleblind, dose-ranging phase III study in patients with acute ischemic stroke and MRI perfusion/diffusion mismatch. Patients were treated with IV desmoteplase $90 \mu \mathrm{g} / \mathrm{kg}, 125$ $\mu \mathrm{g} / \mathrm{kg}$, or placebo within a 3- to 9-h time window. The primary endpoint was 90-day outcome and 186 patients received the treatment. Good clinical outcome was found in $47 \%$ of patients treated with $90 \mu \mathrm{g} / \mathrm{kg}, 36 \%$ with $125 \mu \mathrm{g} / \mathrm{kg}$, and $46 \%$ with placebo. Rates of sICH were of $3.5 \%, 4.5 \%$, and $0 \%$, and case fatality rates were $11 \%, 21 \%$, and $6 \%$, respectively. The overall results of this study did not show any benefit with desmoteplase [54].

The trial investigators attributed this lack of benefit to an inadequate sample size and inconsistencies in mismatch assessments. Additionally, DIAS-2 was based on a lower risk population than the previous desmoteplase trials; this probably resulted in a higher proportion of response rates in the placebo group ( $46 \%$ vs. $22 \%$ in DIAS and $25 \%$ in DEDAS) $[37,51,54]$. DIAS-3 and DIAS-4 were two placebo-controlled, double-blind safety/efficacy trials testing a single IV bolus of desmoteplase at $90 \mu \mathrm{g} / \mathrm{kg}$ within a 3- to 9-h time window in patients with proximal cerebral artery occlusion or high-grade stenosis. The primary outcome was modified Rankin Scale (mRS) score 0-2 at 90-days [37]. DIAS-3 enrolled 492 patients (247 assigned to desmoteplase, and 245 to placebo).

No difference in primary outcome as mRS score $0-2$ at day 90 between $121(51 \%)$ patients in the desmoteplase group and $118(50 \%)$ patients in the placebo group (adjusted OR 1.20, 95\% CI 0.79-1.81, $p=0.40$ ) [57]. However, significant difference in outcomes measured with $\mathrm{mRS}$ in patients with small ischemic injury favored desmoteplase over rt-PA (OR 2.59; 95\% CI 1.21-5.51; $p=0.0139$ ). Interestingly, patients treated over $7 \mathrm{~h}$ from onset had better outcomes (OR 1.59; 95\% CI 1.00-2.53; $p=0.0494)$. There was no difference in case fatality $(10 \%$ in both groups), serious adverse events (27\% vs. $29 \%)$, 


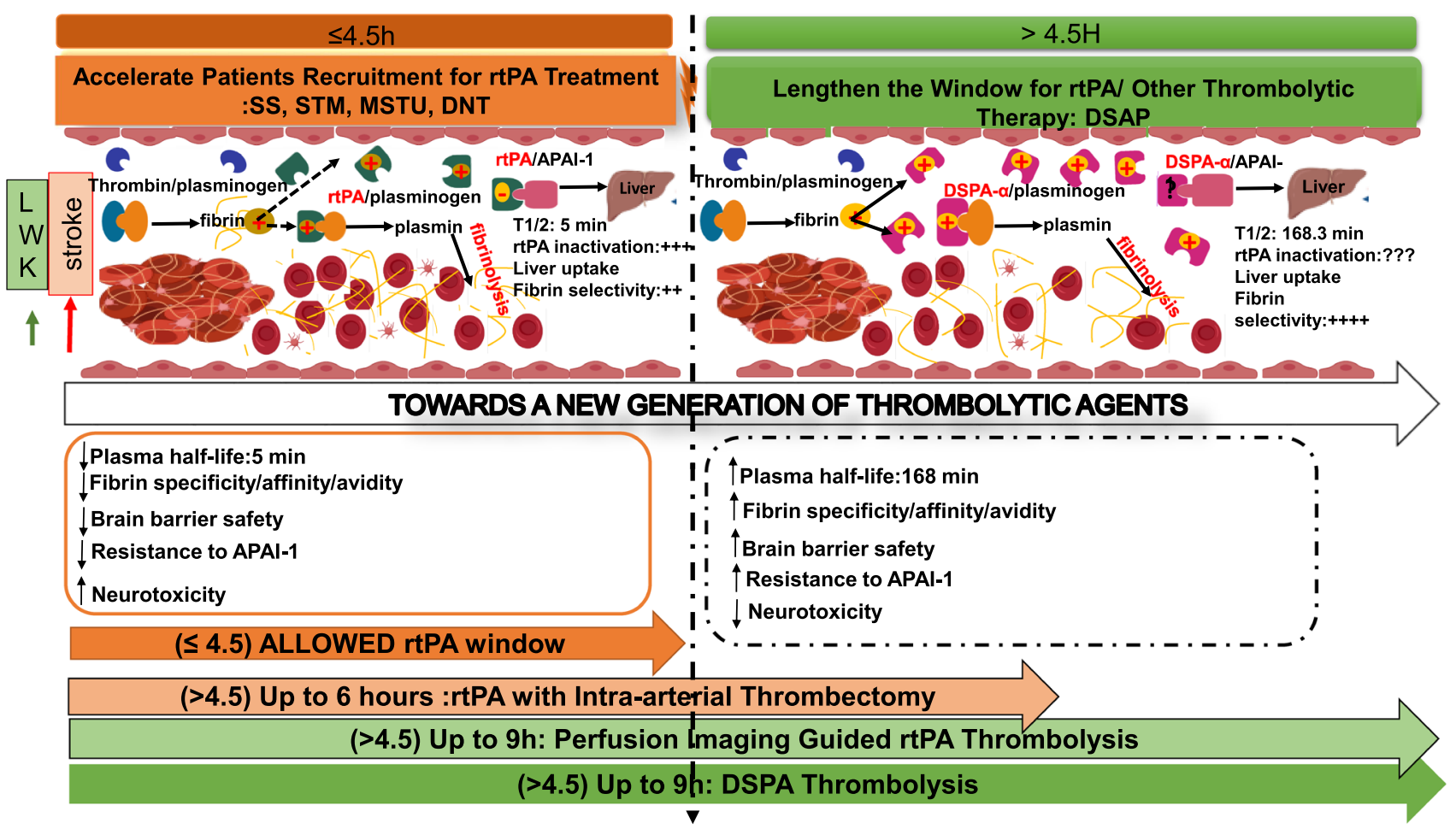

Fig. 4 Schematic comparison between tissue-type plasminogen activator (right panel) and desmoteplase (left panel); two serine protease enzymes that function as an essential catalyst in thrombolysis. Both enzymes catalyze the conversion of plasminogen to plasmin, which is the enzyme responsible for breaking down fibrin blood clots in response to aggregation of activated platelets. However, desmoteplase presents with higher resistance to tissue-type plasminogen activator/plasminogen activator inhibitor-1(PAI-1), a longer half-life, and binds with higher avidity to fibrin but with less neurotoxicity compared to tissue-type plasminogen activator. $S S$ stroke scale, STM stroke telemedicine, $M S T U$ mobile stroke treatment unit, $D N T$ door

frequency of sICH (3\% vs. $2 \%)$, symptomatic cerebral oedema ( $2 \%$ vs. $2 \%$ ), or major hemorrhage ( $4 \%$ vs. $6 \%$ ) in the two groups, respectively. This study showed that desmoteplase was safe, but that it did not improve functional outcomes when given to patients with ischemic stroke and major cerebral artery occlusion between 3 and $9 \mathrm{~h}$ of symptom onset [57].

The recruitment into DIAS4 has been stopped as the result of DIAS3 indicated that the study was unlikely to reach its primary endpoint with the current protocol [56].

DIAS-J (Clinical Study of Desmoteplase in Japanese Patients with Acute Ischemic Stroke) followed the DIAS-3 and DIAS-4 studies. It evaluated safety and tolerability of IV desmoteplase at two doses $(70 \mu \mathrm{g} / \mathrm{kg}$ and $90 \mu \mathrm{g} / \mathrm{kg})$ versus placebo administered from 3 to $9 \mathrm{~h}$ of acute ischemic stroke in a Japanese population. The primary endpoint was the presence of sICH within $72 \mathrm{~h}$ post-treatment, observed in two patients treated with placebo and in one patient to-needle time : Endothelial cell; $>$ : Thrombin enzyme; C.: Thrombin/plasminogen complex; 5 : Alteplase enzyme; Slightly Activated rtPA; $C$ : Alteplase/plasminogen complex; $\quad$ rtPA /Plasminogen activator inhibitor-1(PAI-1); $\odot$ : Inhibition; : Blood clot; $N$ : Fibrin; $\bigcirc$ : Red blood cell; + : Activated platelet; $\odot$ : Low fibrin specificity/affinity/avidity; + : High fibrin specificity/affinity/avidity; $§ ~ §:$ Desmoteplase (DSPA- $\alpha 1$ ); 2 : Desmoteplase/ plasminogen complex; $\Psi$ : Highly activated DSAP- $\alpha 1$; Desmoteplase/PAI-1 complex; $\mathbf{\uparrow}$ : Increase; : Decrease; $?$ : Effect still questioned

intravenously treated with $70 \mu \mathrm{g} / \mathrm{kg}$ of desmoteplase. The rates of any sICH were $43.8 \%$ in patients treated with placebo, $50 \%$ in $70 \mu \mathrm{g} / \mathrm{kg}$ desmoteplase, and $56.3 \%$ in $90 \mu \mathrm{g} /$ $\mathrm{kg}$ desmoteplase groups. Overall, IV desmoteplase at both 70 and $90 \mu \mathrm{g} / \mathrm{kg}$ doses had a favorable safety profile and was well tolerated in Japanese patients with acute ischemic stroke when administered 3-9 h after stroke symptoms onset [58].

\subsection{Results of Systematic Reviews and Meta-Analysis}

In a post hoc analysis, Fiebach et al. grouped patients from DIAS, DEDAS, and DIAS-2 according to Thrombolysis in Myocardial Infarction (TIMI) vessel status. The results showed that, in DIAS-2, 70\% of patients had normal flow or low-grade stenosis as per the TIMI criteria (TIMI 2-3), and that a majority of them had a favorable outcome. Moreover, 
patients with vessel occlusion or high-grade stenosis (TIMI $0-1)$ showed a favorable outcome in $18 \%$ of placebo-treated patients and in $36 \%$ and $27 \%$ of those treated with IV desmoteplase at $90 \mu \mathrm{g} / \mathrm{kg}$ and $125 \mu \mathrm{g} / \mathrm{kg}$, respectively. A pooled analysis reported an OR of 4.144 (95\% CI 1.40-2.23; $p=0.01$ ) favoring desmoteplase over placebo; no effect of the medication was shown in patients without significant stenosis (OR 1.109). These results point toward the efficacy of desmoteplase in patients with mismatch and proximal vessel occlusion or severe stenosis [59].

Additionally, a systematic review and meta-analysis by $\mathrm{Li}$ et al in 2017, pooled data from the 6 different randomized clinical trials (RCTs) (DIAS 2001, DEDAS 2003, DIAS-2 2005, DIAS-3 2009, DIAS-J 2010, and DIAS-4 2014) on IV desmoteplase treatment of acute ischemic stroke patients within 3-9 $\mathrm{h}$ after symptom onset.

This analysis has been conducted in order to evaluate asymptomatic intracerebral hemorrhage, good clinical outcome at 90 days, reperfusion $4-8 \mathrm{~h}$ post-treatment, and symptomatic intracerebral hemorrhage and death rates for respective measurements of desmoteplase's efficacy and safety. Altogether, the above described six trials reported data on a total of 1071 patients who received desmoteplase as a thrombolysis treatment at $3 \mathrm{~h}$ post-onset. The results of all doses combined have shown that desmoteplase was associated with increased reperfusion (OR 1.57; 95\% CI, $1.10-2.24 ; p=0.01$ vs. control). In addition, the results of subgroup analysis showed that desmoteplase $90 \mu \mathrm{g} / \mathrm{kg}$ (OR 1.53 ; 95\% CI 1.07-2.21; $p=0.02$ vs. control) and $125 \mu \mathrm{g} /$ kg (OR 4.07; 95\% CI 1.16-14.24; $p=0.03$ vs. control) were associated with an increase in reperfusion with a tendency to increase asymptomatic intracerebral hemorrhage (OR 1.25; 95\% CI 0.97-1.62; $p=0.09$ vs. control). However, no increase sICH and death rate were noted with desmoteplase and the difference in the clinical response at 90 days (OR 1.14; 95\% CI 0.88-1.49; $p=0.31$ vs. control) was not significant [60]. On the other hand, a second systematic review and meta-analysis of five pooled RCTs performed by Elmaraezy et al. on a total of 821 patients was in accordance with the first one, and favored desmoteplase over placebo in terms of reperfusion 4-24 h post-treatment (OR 1.49, 95\% CI 1.02, 2.19). However, the same study failed to confirm the efficacy endpoint at 90 days (OR $1.16,95 \%$ CI 0.86 , 1.55 ) and to report significant differences in primary safety outcomes (sICH: OR 1.29, 95\% CI 0.53, 3.16, and mortality within 90 days: OR $1.20,95 \%$ CI $0.73,1.97)$. The discrepancy between the two studies can be attributed to different factors, such as different pooled effect size, and, more importantly, to the study design, such as differences in inclusion and exclusion criteria [61].

Nevertheless, a meta-analysis by Grant et al. [62] aimed to relate baseline angiography features in acute ischemic patients with the accurate prediction of later response to IV thrombolytics in ischemic stroke. Therefore, angiograms from the IST-3 (Third International Stroke Trial) were analyzed, and angiography findings were compared and tested for interactions with alteplase and desmoteplase. Moreover, all available angiography data from other RCTs on IV thrombolytics were also meta-analyzed; 2 trials on IV alteplase (288 patients from IST-3 and 87 from the Echoplanar Imaging Thrombolytic Evaluation Trial) and 3 trials on IV desmoteplase (216 patients from DIAS, DIAS-2, and DEDAS) were included. Findings of this study have shown no significant interaction between angiography findings and alteplase effect on the Oxford Handicap Scale $(p \geq 0.075)$ in IST-3.

However, meta-analysis of five trials of alteplase or desmoteplase, including the IST-3 trial, showed the advantageous effect of thrombolytics on the study primary outcome $(\mathrm{OR}>1)$ in patients with arterial obstruction (OR 2.07; 95\% CI 1.18-3.64; $p=0.011$ ) versus those without arterial obstruction (OR $0.88 ; 95 \%$ CI $0.58-1.35 ; p=0.566$ ) ( $p$ for interaction 0.017) [62].

Consequently, it is plausible to speculate that there may still be a benefit from desmoteplase in late-treated patients selected by MRI with small ischemic lesions when compared with rtPA-treated patients. This may require further studies in the subpopulation of patients not covered by the current rt-PA licensing, such as wake-up strokes or strokes beyond the 4.5- to 6-h window.

\section{Conclusions}

It is important to note that, in light of the recent progress that has been made and the ongoing development of thrombolytic drugs, desmoteplase has been largely reported as a safe and well-tolerated alternative in stroke subjects.

Plasma fibrinolytic activity is linearly related to its blood concentration. Administration of desmoteplase leads to transitory derangement of clotting parameters which normalize within 4-12 h. Desmoteplase was tested in myocardial infarction and pulmonary embolism, and showed promising results versus alteplase.

In ischemic stroke trials, desmoteplase was linked to increased rates of symptomatic intracranial hemorrhages (including fatal ones) and case fatality, but no clear relationship to the dose of the medication was identified. The post hoc analyses point toward a benefit of this medication in patients with a mismatch and proximal stenosis or occlusion. Data from most recent studies led to the termination of further clinical development of this compound in acute ischemic stroke. The story of desmoteplase reiterates a frequent phenomenon in this indication. Due to its promising properties, desmoteplase may add to treatment of ischemia with an extension of the time window, with a special 
emphasis on patients presenting outside the 4.5-h thrombolysis window with wake-up strokes and strokes of unknown onset. In addition, the recent rise of interventional thrombolysis as routine practice is changing the whole landscape of the management of acute ischemic stroke. No matter the developments in other areas of stroke care, one needs to consider the lack of direct transposition of theoretical models and basic science into clinical effectiveness. Thus, considering that thrombolytic therapy is sometimes accompanied by harmful hemorrhagic insults, it is very important for a window of time to be established wherein therapy can safely be performed. More basic and clinical studies have to be developed to come up with next-generation thrombolytics.

\section{Declarations}

Funding No sources of funding were used to assist with the preparation of this review.

Conflicts of Interest Authors declare no conflicts of interest, which might be relevant to the content of this review.

Authors' Contribution Bartlomiej Piechowski-Jozwiak conceived the review idea, the manuscript design and initiated drafting and coordination. Emna Abidi elaborated writing sections and prepared the article figure. Wasim S. El Nekidy helped to draft and revise the manuscript. Julien Bogousslavsky helped to draft and revise the manuscript. All authors read and approved the final manuscript.

Availability of Data and Material Not applicable

Code Availability Not applicable

Ethics Approval Not applicable

Consent to Participate Not applicable

Consent for Publication Not applicable

Acknowledgements The authors would like to thank Dr. J. Bloggs for assistance with figure preparation/writing.

\section{References}

1. Centers for Disease Control and Prevention. Underlying cause of death, 1999-2018. CDC WONDER online database. Atlanta: Centers for Disease Control and Prevention; 2018. https://wonder. cdc.gov/ucd-icd10.html. Accessed Mar12, 2020.

2. Virani SS, Alonso A, Benjamin EJ, Bittencourt MS, Callaway CW, Carson AP, et al. Heart disease and stroke statistics 2020 update: a report from the American Heart Associationexternal icon. Circulation. 2020;141:139-596.

3. Lopez AD, Mathers CD, Ezzati M, Jamison DT, Murray CJ. Global and regional burden of disease and risk factors 2001: systematic analysis of population health data. Lancet. 2006;367:1747-57.

4. Adogu POU, Ubajaka CF, Emelumadu OF, Alutu COC. Epidemiologic transition of diseases and health-related events in developing countries: a review. Am J Med Sci. 2015;5:150-7.
5. Pearce WJ. Epigenetics: an expanding new piece of the stroke puzzle. Transl Stroke Res. 2011;2:243-7.

6. Kassis H, Shehadah A, Chopp M, Zhang ZG. Epigenetics in stroke recovery. Genes. 2017;8(3):89.

7. Actilyse, Summary of Product.Characteristics. http://www. medicines.org.uk/emc/medicine/308\#INDICATIONS. Accessed Mar 12, 2020

8. ESO Guideline Directory- European Stroke Organisation. http:// www.eso-stroke.org/pdf/ESO_Guideline Update Jan 2009. Accessed Mar 12, 2020.

9. Wardlaw JM, Koumellis P, Liu M. Thrombolysis (different doses, routes of administration and agents) for acute ischaemic stroke. Cochrane Database Syst Rev. 2013;5: CD000514.

10. Huang X, Moreton FC, Kalladka D, Cheripelli BK, MacIsaac R, Tait RC, Muir KW. Coagulation and fibrinolytic activity of tenecteplase and alteplase in acute ischemic stroke. Stroke. 2015;46(12):3543-6.

11. Furlan A, Higashida R, Wechsler L, Gent M, Rowley H, Kase C, Pessin M, Ahuja A, Callahan F, Clark WM, Silver $\mathrm{F}$, Rivera F. Intra-arterial prourokinase for acute ischemic stroke. The PROACT II study: a randomized controlled trial. Prolyse in acute cerebral thromboembolism. JAMA. 1999;282(21):2003-11.

12. Baird AE, Jackson R, Weijun J. Tenecteplase for acute ischemic stroke treatment. Sem Neurol. 2021;41(1):28-38.

13. Alemseged F, Ng FC, Williams C, Puetz V, Boulouis G, Kleinig TJ, Rocco A, Wu TY, Shah D, Arba F, Kaiser D, Di Giuliano F, Morotti A, Sallustio F, Dewey HM, Bailey P, O’Brien B, Sharma G, Bush S, Dowling R, Diomedi M, Churilov L, Yan B, Parsons MW, Davis SM, Mitchell PJ, Yassi N, Campbell BCV, BATMAN study group and EXTEND IA TNK study group. Tenecteplase vs Alteplase before endovascular therapy in basilar artery occlusion. Neurology. 2021;96(9):e1272-7.

14. The National Institute of Neurological Disorders and Stroke (NINDS) rtPA Stroke Study Group. Tissue plasminogen activator for acute ischemic stroke. N Engl J Med. 1995;333:1581-7.

15. Hacke W, Kaste M, Bluhmki E, Brozman M, Dávalos A, Guidetti D, Larrue V, Lees KR, Medeghri Z, Machnig T, Schneider D, von Kummer R, Wahlgren N, Toni D. Thrombolysis with alteplase 3 to $4.5 \mathrm{~h}$ after acute ischemic stroke. N Engl J Med. 2008;359:1317-29.

16. Wahlgren N, Ahmed N, Dávalos A, Hacke W, Millán M, Muir K, Roine RO, Toni D, Lees KR, SITS investigators. Thrombolysis with alteplase 3-4.5 hours after acute ischaemic stroke (SITSISTR): an observational study. Lancet. 2008;372(9646):1303.

17. Maestroni A, Mandelli C, Manganaro D, Zecca B, Rossi P, Monzani $\mathrm{V}$, Torgano G. Factors influencing delay in presentation for acute stroke in an emergency department in Milan, Italy. Emerg Med J. 2008;25(6):340-5.

18. Clemens MS, Andrew JR, Adam SA, Mandy JB, WCF, Robert FJ, Michael RL, Rabih GT, Erol V, Melanie W and Alejandro MS. Delayed presentation of acute ischemic strokes during the COVID-19 crisis. J Neurointerv Surg. 2020; 2020-016299.

19. Prabhakaran S, Ruff I, Bernstein RA. Acute stroke intervention: a systematic review. JAMA. 2015;313(14):1451-62.

20. Lakhan SE, Kirchgessner A, Hofer M. Inflammatory mechanisms in ischemic stroke. Therapeutic approaches. J Transl Med. 2009;7:97.

21. Kadir RRA, Bayraktutan U. Urokinase plasminogen activator: a potential thrombolytic agent for ischaemic stroke. Cell Mol Neurobiol. 2020;40:347-55.

22. Lundbeck discontinues further development of desmoteplase 2014 profit guidance range narrowed. Lundbeck discontinues further development of desmoteplase; 2014 profit guidance range narrowed I FierceBiotech. Accessed Aug 10, 2021. 
23. Reed M, Kerndt CC, Nicolas D. Alteplase. In: StatPearls. FL: Treasure Island 2020.

24. Wang W, Li M, Chen Q, Wang J. Hemorrhagic transformation after tissue plasminogen activator reperfusion therapy for ischemic stroke: mechanisms, models, and biomarkers. Mol Neurobiol. 2015;52:1572-9.

25. Meretoja A, Keshtkaran M, Saver JL, Tatlisumak T, Parsons MW, Kaste M, et al. Stroke thrombolysis. Stroke. 2014;45:1053-8.

26. Benedict CR, Refino CJ, Keyt BA, Pakala R, Paoni NF, Thomas GR, et al. New variant of human tissue plasminogen activator (TPA) with enhanced efficacy and lower incidence of bleeding compared with recombinant human TP. Circulation. 1995;92:3032-40.

27. Liberatore GT, Samson A, Bladin C, Schleuning WD, Medcalf LR. Vampire bat salivary plasminogen activator (desmoteplase): a unique fibrinolytic enzyme that does not promote neurodegeneration. Stroke. 2003;34:537-43.

28. Röther J, Ford GA, Thijs VN. Thrombolytics in acute ischaemic stroke: historical perspective and future opportunities. Cereb Dis. 2013;35:313-9.

29. Parsons MW, Miteff F, Bateman GA, Spratt N, Loiselle A, Attia $\mathrm{J}$, et al. Acute ischemic stroke: imaging-guided tenecteplase treatment in an extended time window. Neurology. 2009;72:915-21.

30. Parsons M, Spratt N, Bivard A, Campbell B, Chung K, Miteff F, et al. A randomized trial of tenecteplase versus alteplase for acute ischemic stroke. N Engl J Med. 2012;366:1099-107.

31. Warach SJ, Dula AN, Milling JT. Tenecteplase thrombolysis for acute ischemic stroke. Stroke. 2020;51:3440-51.

32. Gardell SJ, Duong LT, Diehl RE, et al. Isolation, characterization, and cDNA cloning of a vampire bat salivary plasminogen activator. J Biol Chem. 1989;264(30):17947-52.

33. Gardell SJ, Hare TR, Bergum PW, et al. Vampire bat salivary plasminogen activator is quiescent in human plasma in the absence of fibrin unlike human tissue plasminogen activator. Blood. 1990;76(12):2560-4.

34. Roessler FC, Wang Z, Schumacher S, Ohlrich M, Kaps M, Menciassi A, Eggers J. In vitro examination of the thrombolytic efficacy of desmoteplase and therapeutic ultrasound compared with rt-PA. Ultrasound Med Biol. 2015;41(12):3233-40. https://doi.org/10. 1016/j.ultrasmedbio.2015.07.007.

35. Bringmann P, Gruber D, Liese A, et al. Structural features mediating fibrin selectivity of vampire bat plasminogen activators. J Biol Chem. 1995;270(43):25596-603.

36. Kratzschmar J, Haendler B, Langer G, Boidol W, Bringmann P, Alagon A, Donner P, Schleuning WD. The plasminogen activator family from the salivary gland of the vampire bat Desmodus rotundus, cloning and expression. Gene. 1991;105:229-37.

37. Piechowski-Jozwiak B, Bogousslavsky J. The use of desmoteplase (bat saliva) in the treatment of ischaemia. Expert Opin Biol Ther. 2013;13(3):447-53.

38. Schleuning WD, Alagon A, Boidol W, et al. Plasminogen activators from the saliva of Desmodus rotundus (common vampire bat): unique fibrin specificity. Ann NY Acad Sci. 1992;667:395-403.

39. Medcalf RL. Desmoteplase: discovery, insights and opportunities for ischemic stroke. Br J Pharmacol. 2012;165(1):75-89.

40. López-Atalaya JP, Roussel BD, Ali C, et al. Recombinant Desmodus rotundus salivary plasminogen activator crosses the bloodbrain barrier through a low-density lipoprotein receptor-related protein-dependent mechanism without exerting neurotoxic effects. Stroke. 2007;38(3):1036-43.

41. Elmira M, Karim M, Ali JN, Hamid M. Design and production of new chimeric reteplase with enhanced fibrin affinity: a theoretical and experimental study. J Biomol Struct Dyn. 2021;39(4):1321-33.

42. Dafer RM, Biller J. Desmoteplase in the treatment of acute ischemic stroke. Expert Rev Neurother. 2007;7:333-7.
43. Reddrop C, Moldrich RX, Beart PM, Farso M, Liberatore GT, Howells DW, Petersen KU, Schleuning WD, Medcalf RL. Vampire bat salivary plasminogen activator (desmoteplase) inhibits tissue-type plasminogen activator-induced potentiation of excitotoxic injury. Stroke. 2005;36(6):1241-6.

44. Larsen LF, Buchberg Petersen K, Areberg J, Pihl S. A Phase I study of Desmoteplase in healthy Japanese and Caucasian men. In: 7th World Stroke Congress, October 13-16, 2010; Seoul, Korea (Personal communication; with permission from Lundbeck $\mathrm{A} / \mathrm{S})$

45. Gusev EI, Martynov MY, Yasamanova AN, Nikonov AA, Markin SS, Semenov AM. Thrombolytic therapy of ischemic stroke. Nevrol Psikhiatr Zh, Korsakova Im SS. 2018;118(12. Vyp. 2):4-14.

46. Deborah RB, Peter H, Simon P, Christoph T, Katrin V. Corneal and scleral permeability of Desmoteplase in different species. Vet Ophthalmol. 2020;23(5):785-91.

47. Schleuning WD. Vampire bat plasminogen activator DSPA-Alfa-1 (Desmoteplase): a thrombolytic drug optimized by natural selection. Hemostasis. 2001;31:118-22.

48. Baruah DB, Dash RN, Chaudhari MR, Kadam SS. Plasminogen activators: a comparison. Vascul Pharmacol. 2006;44(1):1-9.

49. Bivard A, Lin L, Parsons M. Review of stroke thrombolytics. J Stroke. 2013;15(2):90-8.

50. Tebbe U, Bramlage P, Graf A, Lechleitner P, Bode C, Riess FC, Clemens N, Al-Rawi Y, Kostantinides S, Goldhaber SZ. Desmoteplase in acute massive pulmonary thromboembolism. Thromb Haemost. 2009;101:557-62.

51. Patel R, Ispoglou S, Apostolakis S. Desmoteplase as a potential treatment for cerebral ischaemia. Expert Opin Investig Drugs. 2014;23(6):865-73.

52. Hacke W, Albers G, Al-Rawi Y, et al. The Desmoteplase in Acute Ischemic Stroke Trial (DIAS): a phase II MRI-based 9-hour window acute stroke thrombolysis trial with intravenous desmoteplase. Stroke. 2005;36(1):66-73.

53. Furlan AJ, Eyding D, Albers GW, et al. Dose Escalation of Desmoteplase for Acute Ischemic Stroke (DEDAS): evidence of safety and efficacy 3 to 9 hours after stroke onset. Stroke. 2006;37(5):1227-31.

54. Hacke W, Furlan AJ, Al-Rawi Y, Davalos A, Fiebach JB, Gruber F, Kaste M, Lipka LJ, Pedraza S, Ringleb PA, Rowley HA, Schneider D, Schwamm LH, Leal JS, Söhngen M, Teal PA, WilhelmOgunbiyi K, Wintermark M, Warach S. Intravenous desmoteplase in patients with acute ischaemic stroke selected by MRI perfusiondiffusion weighted imaging or perfusion CT (DIAS-2): a prospective, randomised, double-blind, placebo-controlled study. Lancet Neurol. 2009;8(2):141-50.

55. Efficacy and safety study of desmoteplase to treat acute ischemic stroke (DIAS-3). 2015. http://clinicaltrials.gov/ct2/show/NCT00 790920/. Accessed Jul 2, 2020.

56. Efficacy and safety study of desmoteplase to treat acute ischemic stroke (DIAS-4). 2017. http://clinicaltrials.gov/ct2/show/NCT00 856661/. Accessed Jul 2, 2020.

57. Albers GW, von Kummer R, Truelsen T, Jensen JK, Ravn GM, Grønning BA, Chabriat H, Chang KC, Davalos AE, Ford GA, Grotta J, Kaste M, Schwamm LH, Shuaib A, DIAS-3 Investigators. Safety and efficacy of desmoteplase given 3-9 hours after ischaemic stroke in patients with occlusion or high-grade stenosis in major cerebral arteries (DIAS-3): a double-blind, randomised, placebo-controlled phase 3 trial. Lancet Neurol. 2015;14(6):575-84.

58. Mori E, Minematsu K, Nakagawara J, Hasegawa Y, Nagahiro S, Okada Y, Truelsen T, Lindsten A, Ogawa A, Yamaguchi T, DIASJ Investigators. Safety and tolerability of desmoteplase within 3 to 9 hours after symptoms onset in Japanese patients with ischemic stroke. Stroke. 2015;46(9):2549-54. 
59. Fiebach JB, Al-Rawi Y, Wintermark M, Furlan AJ, Rowley HA, Lindstén A, Smyej J, Eng P, Warach S, Pedraza S. Vascular occlusion enables selecting acute ischemic stroke patients for treatment with desmoteplase. Stroke. 2012;43(6):1561-6.

60. Li X, Ling L, Li CQ. Efficacy and safety of desmoteplase in acute ischemic stroke patients: a systematic review and meta-analysis. Medicine. 2017;96: e6667.

61. Elmaraezy A, Abushouk AI, Saad S, Eltoomy M, Mahmoud O, Hassan HM, et al. Desmoteplase for acute ischemic stroke: a systematic review and metaanalysis of randomized controlled trials. CNS Neurol Disord Drug Targets. 2017;16:789-99.

62. Grant M, Rüdiger VK, Alessandro A, Philip M, Matthew EA, Bernard Y, Andrew MD, Andrew JF, Robin JS, Eleni S, Jeb P, David P, Richard IL, Peter AG, Joanna MW. Arterial obstruction on computed tomographic or magnetic resonance angiography and response to intravenous thrombolytics in ischemic stroke. Stroke. 2017;48:353-436. 